\title{
Presentación de Otros Temas del Número 78
}

\section{Presentation of Other Themes from Number 78}

\author{
Irma Munguía Zararain \\ Universidad Autónoma Metropolitana-Iztapalapa, \\ Ciudad de México, México \\ ORCID: https://orcid.org/0000-0003-1873-905x
}

ISSN: ISSN-0I85-4259; e- ISSN: 2007-9176 DoI: http://dx.doi.org/I0.28928/revistaiztapalapa/782015/pot/munguiazataraini

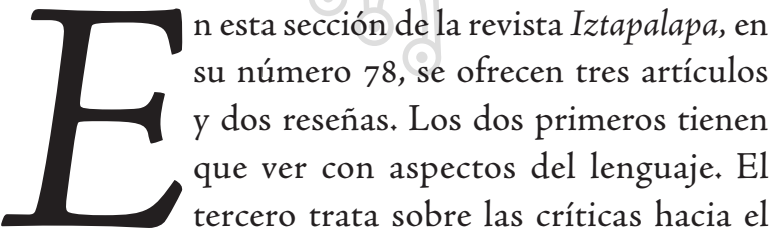
pensamiento utópico. Las reseñas abordan el papel de internet como interfaz entre los seres humanos y las máquinas, así como la irrupción de la esfera privada en el espacio público.

En el artículo "Un modelo de pauta de corrección para ensayos argumentativos", Martha Jurado y Viviana Oropeza describen las características de un patrón de corrección analítica para poder evaluar las habilidades argumentativas en los estudiantes del nivel de bachillerato, cuando se les pide como tarea escribir ensayos. Esta pauta se basó en el Marco Curricular Común (MCC) del bachillerato. Como es sabido, evaluar la producción escrita es una labor muy compleja debido a las dificultades de señalar las rúbricas correspondientes; las autoras plantean que esta pauta de corrección 
pudiera ser una guía muy útil para los profesores y para los estudiantes, puesto que estos tomarían conciencia de los aspectos que deben considerarse en la elaboración y corrección de un ensayo. Siempre se ha pensado que la evaluación de la escritura puede ser muy subjetiva, pero creo que si se cuenta con una pauta de corrección como la que proponen Jurado y Oropeza se lograría un avance muy importante en esa dirección.

En el segundo artículo, "La formación lingüística de los profesores de primaria: el reto de enseñar español”, Elia Sánchez analiza las ventajas que tendría incluir un eje de contenidos lingüísticos en los planes y programas de la formación de docentes. Como es sabido, la formación de profesores de español carece de temas específicos que permitan reflexionar sobre el sistema de la lengua. Es interesante considerar que, por ejemplo, el trabajo explícito con estos contenidos seguramente ha contribuido al éxito de algunos sistemas educativos calificados como los mejores en el mundo - como es el caso del sistema finlandés. En el artículo se plantea que si se ofreciera una formación lingüística adecuada a quienes estudian para profesores de educación básica, seguramente se podría contribuir a superar el rezago educativo que se tiene en México, en lo que se refiere al manejo de habilidades en español.

El tercer artículo, "El pensamiento utópico y las críticas de Popper, Molnar y Marcuse", de Lucas E. Misseri, explica qué se entiende por utopía y por pensamiento utópico, a partir de las diferentes críticas de esos tres autores; además, muestra cómo estas críticas fracasan, dado que confunden las características de las utopías históricas particulares con la facultad de crearlas o pensarlas. El autor muestra cómo los tres críticos terminan confundiendo el concepto de utopía con el pensamiento utópico. En el caso de Popper, hace su crítica liberal de corte psicologista, Molnar la hace desde su postura de creyente conservador $y$, finalmente, Marcuse parte del neomarxismo.

Las reseñas presentan libros sobre temas muy polémicos y novedosos: en la primera de ellas, Emilia Perujo Lavín plantea que en la obra Invisible Users. Youth in the Internet Cafés of Urban Ghana, la autora Jenna Burrell se aboca a la interfaz humano-máquina, surgida después de la creación de los llamados café-internet, en donde no se ofrece café ni se interactúa con los asistentes, sino que la comunicación se establece entre cada persona de manera aislada, con otras personas que están en otras latitudes, típicamente en el extranjero, y esa comunicación se logra por medio de la computadora que cada uno tiene enfrente. El libro se refiere a lo que ocurre en una ciudad de Ghana, en estos cafés; los usuarios se liberan de su identidad dado que pueden cambiar de sexo, de nacionalidad, de edad — en cierta forma se hacen "invisibles"-, para tratar de engañar a extranjeros, mediante estafas de diversos tipos. 
Por su parte, Mario Zaragoza Ramírez reflexiona sobre el libro A Private Sphere. Democracy in a Digital Age de Zizi Papacharissi. En el texto se interroga sobre la medida en que estaremos, en esta época de digitalización, ante la posibilidad de que los individuos lleven su esfera privada (definida por la participación democrática) hacia la esfera pública (representada por la tecnología), todo esto a través de internet. Resulta interesante pensar cómo lo íntimo y privado de una casa, un auto o la cocina de una persona pueda irrumpir en lo público, a través de las redes sociales, por ejemplo, dando un like a favor de algún asunto completamente público. A partir de lo anterior, resulta interesante pensar si en esta época de nuevas tecnologías de la información y de la comunicación pudiera hablarse realmente de "nuevos ciudadanos", cuando la cultura popular refuerza en internet actitudes tradicionalmente misóginas y homofóbicas, entre otras prácticas muy arraigadas. 